\title{
An epidemiological study in an Anatolian village environmentally exposed to tremolite asbestos
}

\author{
Y I BARIS,' N BILIR,' M ARTVINLI,' A A SAHIN,' F KALYONCU,' P SEBASTIEN ${ }^{2}$ \\ From the Departments of Chest Diseases and Public Health, ${ }^{\prime}$ Hacettepe University, School of Medicine, \\ Ankara, Turkey, and Dust Disease Research Unit, ${ }^{2}$ School of Occupational Health, McGill University, \\ Montreal, PQ, Canada
}

Tremolite is the most commonly occurring of the amphibole asbestos minerals and is found in a wide range of geological environments. It is an early product of thermal metamorphism of dolomites with silica impurities and is a common contaminant of industrial talc and chrysotile asbestos.

Tremolite is found in some countries in sufficient quantities for commercial exploitation including Italy, Turkey, Pakistan, and South Korea. It can occur in a variety of forms ranging from a fine fibre to a coarse flake like fibre. Although there is some experimental and clinicopathological evidence that fine tremolite is carcinogenic, ${ }^{1-4}$ since it is not used commercially it is given virtually no consideration when the epidemiology and aetiology of asbestos related diseases are considered.

After the detection of four cases of malignant pleural mesothelioma in the small village of Çaparkayi an epidemiological study was performed there.

\section{Materials and methods}

Caparkayi is in the Sabanözü area of the Çankiri district in Turkey, about $90 \mathrm{~km}$ from Ankara (fig 1). The main economic activity is farming and livestock breeding. The houses are made of mudbrick and rocks and there is no asbestos mine nearby.

As the result of migration to the cities to seek employment, the population and the proportion of young people has decreased and the present population is 425 of whom $215(51 \%)$ are aged 20 or over.

A questionnaire was completed for all those over 20 and a physical examination was performed by four physicians. From the questionnaire, information on medical history, smoking habit, occupational exposure to asbestos, and symptoms related to the respiratory system were obtained.

Using a portable Picker model $x$ ray apparatus, standard posteroanterior chest $x$ ray films were taken and the films were evaluated by three chest specialists.

Samples of white stucco which had been used for

Accepted 2 November 1987
Radiological abnormalities in 63 chest $x$ ray flms*

\begin{tabular}{llllll}
\hline & \multicolumn{2}{l}{ No of patients } & & \multicolumn{2}{l}{ Prevalence } \\
\cline { 2 - 4 } Abnormalities & Male & Female & & (\%) & Mean age \\
\hline $\begin{array}{l}\text { Interlober fissure } \\
\text { thickening }\end{array}$ & 17 & 11 & 16.8 & $52.6 \pm 14.5$ \\
$\begin{array}{c}\text { Diffuse interstitial } \\
\text { fibrosis }\end{array}$ & 15 & 11 & 15.6 & $55.2 \pm 20.7$ \\
$\begin{array}{c}\text { Calcified pleural } \\
\text { plaque }\end{array}$ & 16 & 8 & 14.4 & $58.2 \pm 13.6$ \\
$\begin{array}{c}\text { Pleural thickening } \\
\text { Compatible with } \\
\text { tuberculosis }\end{array}$ & 8 & 5 & 7.8 & $61.2 \pm 10.6$ \\
\hline
\end{tabular}

*Some have more than one abnormality.

†Typical calcification with asbestos exposure.

many years by all villagers for indoor and outdoor painting were taken and examined at the Dust Disease Research Unit of McGill University, School of Occupational Health, Canada.

The information about the population and its mortality was obtained from the records of the health centre from 1980 to 1987.

\section{Results}

Everyone aged over 20 lived in houses that were painted with a white stucco obtained from a nearby source.

Chest $x$ ray films were taken from 167 of those aged 20 and over and $63(37.7 \%)$ were found to have radiological abnormalities (table).

The analysis of the white stucco sample showed that it was rich in tremolite asbestos including some very fine fibres (fig 2).

Some of the adult deaths between 1980 and 1987 were from malignant disease; two from mesothelioma and one each from gastric carcinoma and lymphoma.

\section{Discussion}

Mesothelioma is rare and the annual incidence in populations with no exposure to asbestos is about one per million; the risk may be increased by a factor of a 


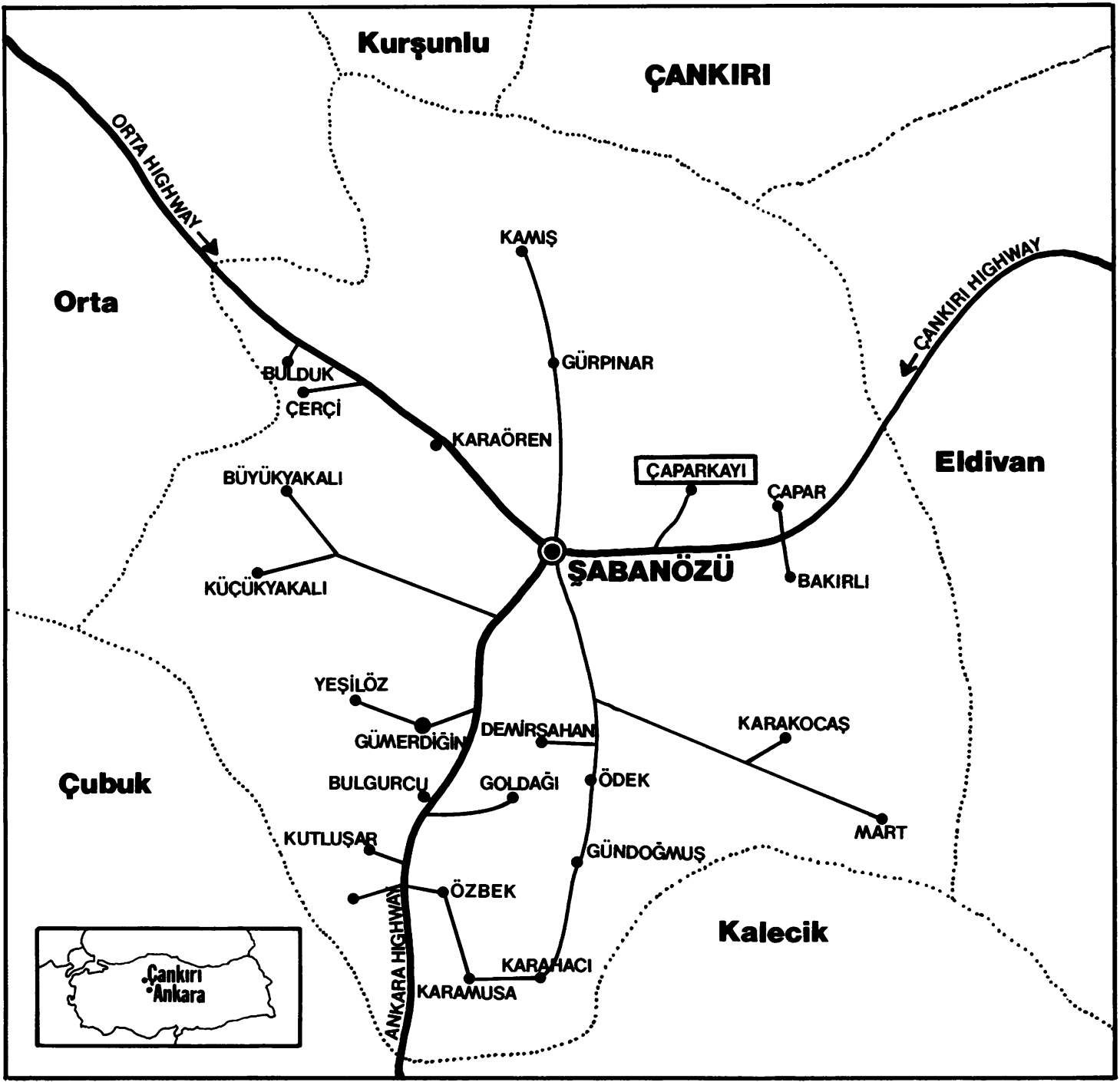

Fig 1 Map of Sabanözü area showing location of Çaparkayi.

thousand or more among those heavily exposed to asbestos. ${ }^{5}$ In a small village with a population of 425 , four cases of mesothelioma occurring in four years is unusual. In the same village there were also patients with pleural asbestosis and diffuse pulmonary fibrosis.

The villagers of Chaparkayi are not occupationally exposed to asbestos but fine and coarse tremolite fibres were found in the bulk sample of white stucco. Thus the villagers may inhale these fibres from the walls of houses painted with the stucco. The natural erosion of asbestos containing soil and the formation of dust from this soil, however, may also produce air pollution.
It is well known that the amphibole form of asbestos is the most important in the aetiology of mesothelioma, in particular crocidolite and amosite. Recent reports, however, have suggested that the serpentine forms may also be implicated in the causation of this disease. This evidence comes from reports of increased rates of mesothelioma in chrysotile miners in Canada ${ }^{3}$ and in workers from a talc mine in New York State. ${ }^{6}$ Both these mines, however, are known to be contaminated with tremolite asbestos, which would appear to be a better candidate as the cause of these mesotheliomas because of its physical structure. Another study by McConnochie et al in Cyprus found that 


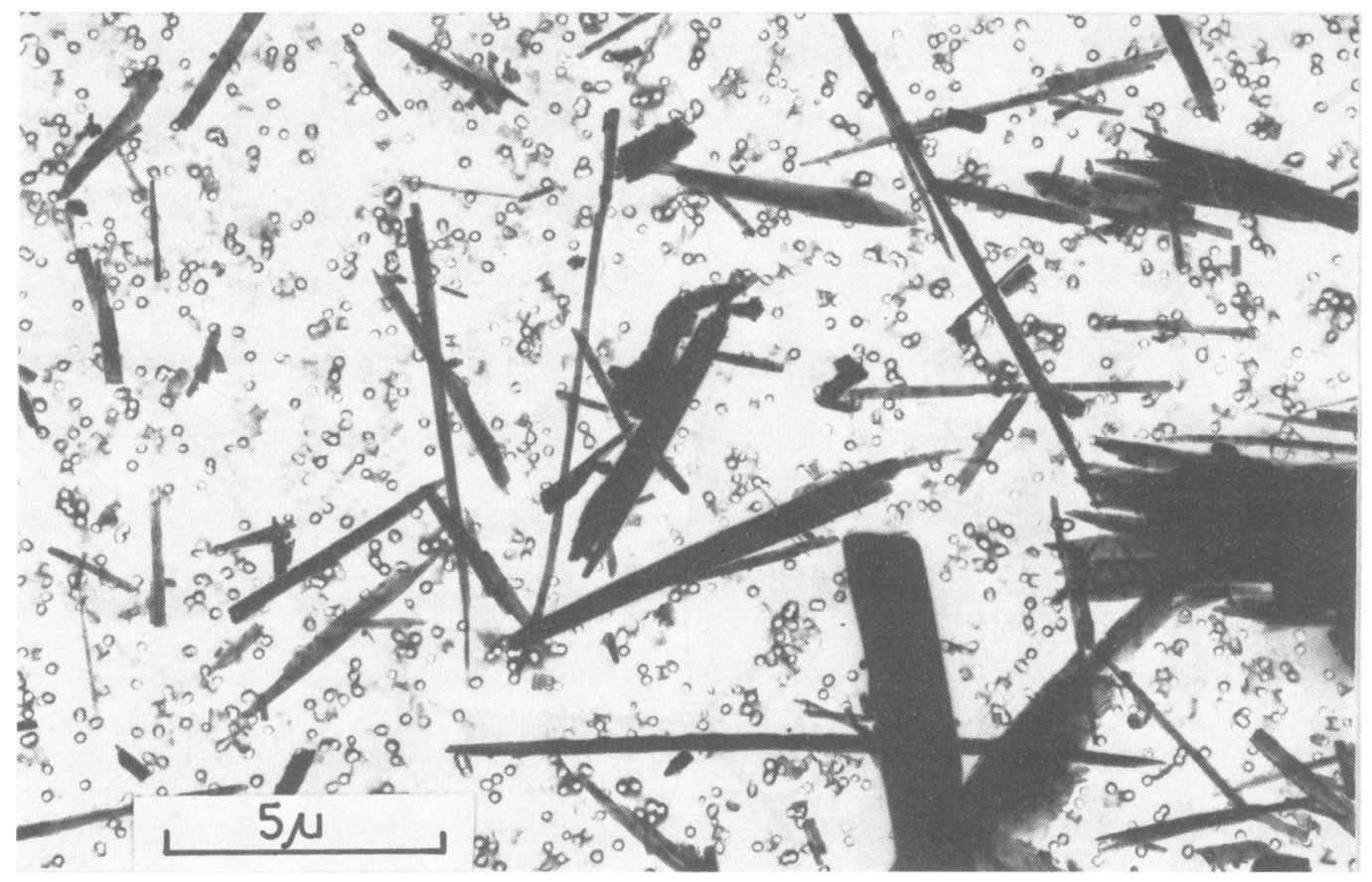

Fig 2 Electron micrograph of Çaparkayi white stucco showing fine and coarse tremolite fibres.

cases of mesothelioma occurred near a pure chrysotile mine. ${ }^{4}$ Once again, environmental studies indicated tremolite contamination of the roof tops of certain houses. Tremolite was also found in patients' lung samples and in sheep lungs and the mines were not considered to be the cause of the mesothelioma.

In the present study the prevalence of parietal and visceral pleural thickening and calcification, pulmonary fibrosis, and pulmonary tuberculosis is high. There is no doubt that calcified pleural plaques are related to exposure to asbestos. Solomon et al suggest that thickening of the interlobar fissure is the best radiological sign of exposure to asbestos. ${ }^{78} \mathrm{~A}$ prevalence of $16.8 \%$ interlobar fissure thickening points to long and heavy exposure to asbestos.

Two patients died from pulmonary tuberculosis and seven more cases were detected by radiological screening. Some of the pleural and parenchymal changes noted may also have been related of tuberculosis. Roviaro et al reported three cases of pulmonary tuberculosis associated with mesothelioma ${ }^{8}$ There are other reports that the incidence of tuberculosis is higher in asbestos workers than in the normal population which may be related to the depression of the immune system reported in those exposed to asbestos. There are also reports that chronic pleuropulmonary tuberculosis may cause mesothelioma in the absence of a history of exposure to asbestos. ${ }^{910}$ We believe, however, that tremolite fibres are the real cause of the high incidence of mesothelioma and of some of the pleural and parenchymal changes in the village. The high incidence of tuberculosis may be primarily due to asbestos related immune depression or simply to a tuberculous endemic.

\section{References}

1 Stanton MF, Lazard M, Tegeris A, et al. Relation of particle dimension to carcinogenicity in amphibole asbestoses and other fibrous minerals. J Natl Cancer Inst 1981;67:965-75.

2 Wagner JC, Chamberlain M, Brown RC, et al. Biological effects of tremolite. Br J Cancer 1982;45:352-60.

3 Churg A, Wiggs B, Depaoli L, et al. Lung asbestos content in chrysotile workers with mesothelioma. Am Rev Respir Dis 1984; 130:1042-5.

4 McConnichie K, Simonato L, Mavrides P, et al. Mesothelioma in Cyprus: the role of tremolite. Thorax 1987;42:342-7.

5 Peto J, Seidman H, Selikoff IJ. Mesothelioma mortality in asbestos workers: implications for models of carcinogenesis and risk assessment. Br J Cancer 1982;45:124-35.

6 Kleinfeld M, Messite J, Zaki MH. Mortality experiences among talc workers: a follow up study. J Occup Med 1974;16:345-9.

7 Solomon A, Irwig LM, Sluis-Cremer GK, et al. Thickening of pulmonary interlobar fissure: exposure-response relationship in crocidolite and amosite miners. $\mathrm{Br}$ J Ind Med 1979;36:195-8.

8 Roviaro G, Sartori F, Calabro F, Varoli F. The association of pleural mesothelioma and tuberculosis. Am Rev Respir Dis 1982;126:569-71.

9 Martinis JU, Radovic VR. Pleural mesothelioma in patients with pulmonary tuberculosis. Dis Chest 1965;47:568-70.

10 Chretien J, Delobel J, Bronet G. Données étiologiques concernant 15 observations de mesotheliomes malins de la plevre. Poumon Coeur 1968;24:549-57. 